ARTIGO ORIGINAL

\title{
Caracterização do lenho e efeito de variáveis meteorológicas no crescimento de Cunninghamia lanceolata no sul do Brasil
}

\author{
Wood characterization and meteorological effects on growth of Cunninghamia \\ lanceolata on southern Brazil
}

\author{
Mário Dobner Júnior ${ }^{1}$ (D), Paulo André Trazzi² (D), Ugo Leandro Belini ${ }^{3}$ (1), \\ Ivanka Rosada de Oliveira ${ }^{4}$ (D), Mario Tomazello-Filho ${ }^{5}$ (1) \\ 1 Universidade Federal de Santa Catarina - UFSC, Curitibanos, SC, Brasil \\ ${ }^{2}$ Universidade Federal do Acre - UFAC, Rio Branco, AC, Brasil \\ ${ }^{3}$ Universidade Tecnológica Federal do Paraná - UTFPR, Curitiba, PR, Brasil \\ "Universidade Estadual Paulista "Júlio de Mesquita Filho" - UNESP, Botucatu, SP, Brasil \\ 5Universidade de São Paulo - USP, Piracicaba, SP, Brasil
}

\begin{abstract}
Como citar: Dobner Júnior, M., Trazzi, P. A., Belini, U. L., Oliveira, I. R., \& Tomazello-Filho, M. (2021). Caracterização do lenho e efeito de variáveis meteorológicas no crescimento de Cunninghamia lanceolata no sul do Brasil. Scientia Forestalis, 49(130), e3471. https://doi.org/10.18671/scifor.v49n130.06
\end{abstract}

\begin{abstract}
Resumo
Cunninghamia lanceolata é indicada para cultivo no planalto sul do Brasil e, embora de potencial reconhecido, não é utilizada comercialmente. Os objetivos do presente estudo foram caracterizar o lenho da madeira de $C$. lanceolata, por meio de microdensitometria de raios $\mathrm{X}$, e avaliar o efeito de variáveis meteorológicas durante 21 anos de formação do lenho e, desta forma, ampliar o conhecimento e possibilidade de uso comercial da espécie. Os resultados indicaram que a densidade aparente média do lenho foi de $0,364 \mathrm{~g} \mathrm{~cm}^{-3}$, semelhante em árvores de menor ou maior diâmetro. Não houve diferenças significativas entre a densidade aparente do lenho formado próximo à medula (juvenil) e o lenho próximo à casca (adulto). O crescimento dos indivíduos foi significativamente e positivamente afetado pela temperatura mínima do mês de junho prévio ao início do período vegetativo, e pela umidade relativa do ar dos meses de março, abril e maio, término do período vegetativo. Além do efeito negativo de geadas no crescimento durante todo o período estudado, a ausência de 4-7 anéis de crescimento na base da árvore indica que geadas são, possivelmente, o maior fator limitante para o estabelecimento de plantios da espécie na região estudada.
\end{abstract}

Palavras-chave: Microdensitomeria; Raios X; Dendrocronologia; Anéis de crescimento; Densidade da madeira.

\begin{abstract}
Cunninghamia lanceolata has been indicated for cultivation on the highlands of southern Brazil, but in spite of its high potential it is not commercially cultivated. This study aimed to characterize the wood of C. lanceolata and evaluate the effects of meteorological variables on the 21-years of wood formation and, therefore, expand the understanding and commercial use possibilities of the species. Results indicate that apparent density was $0.364 \mathrm{~g} \mathrm{~cm}^{-3}$, similar on trees with smaller and bigger diameter. There were no substantial differences between the wood formed close to the pith (juvenile) band the one close to the bark (mature). Growth was significantly and positively affected by the minimum temperature in June previous to the beginning of the vegetative growth period, and by the air relative humidity of March, April and May. Aside from the negative effects of frosts on the growth during the whole period studied, the
\end{abstract}

Fonte de financiamento: Nenhuma.

Conflito de interesse: Nada a declarar.

Autor correspondente: mario.dobner@ufsc.br

Recebido: 9 setembro 2019.

Aceito: 2 abril 2020.

Editor: Paulo Henrique Müller Silva.

(c) (i) Este é um artigo publicado em acesso aberto (Open Access) sob a licença Creative Commons Attribution, que permite uso, distribuição e

c) reprodução em qualquer meio, sem restrições desde que o trabalho original seja corretamente citado. 
absence of 4-7 annual growth rings at tree's base indicates that frosts are probably the main limiting factor for plantation establishment of this species in the studied region.

Keywords: Microdensitometry; X-ray; Dendrochronology; Growth rings; Wood density.

\section{INTRODUÇÃO}

Cunninghamia lanceolata (Lamb.) Hooker, conhecida internacionalmente como 'chinese fir', é considerada a espécie florestal mais importante do sul da China, tanto do ponto de vista econômico como ecológico, principalmente devido ao seu rápido crescimento, além de amplas aplicações industriais, apresentando mais de nove milhões de hectares plantados naquela região (Minghe \& Ritchie, 1999; Lei, 2005; Xiang et al., 2009).

No Brasil, a espécie não é cultivada comercialmente, apesar do reconhecido potencial, com crescimentos entre 28-36 $\mathrm{m}^{3} \mathrm{ha}^{-1}$ ano-1 $^{-1}$ (Empresa Brasileira de Pesquisa Agropecuária, 1988; Dobner Júnior et al., 2017). Sua madeira possui densidade básica de 0,28-0,48 $\mathrm{g} \mathrm{cm}^{-3}$ (Marchiori, 2005; Empresa Brasileira de Pesquisa Agropecuária, 1988) e, embora leve e macia, é considerada excelente para construções (casas, pontes, barcos) por ser naturalmente resistente ao apodrecimento e aos insetos, além de ter boas propriedades para polpação e possibilidades de uso em painéis particulados (Minghe \& Ritchie, 1999).

Em coníferas, a qualidade da madeira é o resultado da formação dos anéis anuais de crescimento em termos de largura e espessura das paredes dos traqueídeos, distribuição dos lenhos iniciais e tardios, transição de lenho juvenil para adulto e a proporção destes. Todos estes possuem implicações diretas na densidade da madeira, quesito intimamente ligado à qualidade do lenho e que define usos e aplicações.

O não cultivo comercial de $C$. lanceolata no sul do Brasil é, possivelmente, resultado da falta de conhecimento, tanto dos aspectos relacionados à madeira, como aos relacionados ao cultivo e, mais especificamente, ao efeito de variáveis meteorológicas no crescimento da espécie. Neste contexto, o primeiro objetivo do presente estudo foi caracterizar o lenho da madeira de $C$. lanceolata cultivada no sul do Brasil por meio de microdensitometria de raios $X$. Adicionalmente, avaliou-se o efeito de variáveis meteorológicas no crescimento, durante 21 anos de formação do lenho.

\section{MATERIAL E MÉTODOS}

\subsection{Origem dos dados}

As árvores de Cunninghamia lanceolata objeto de estudo foram obtidas em um plantio estabelecido em 1990, com espaçamento de 2,5 m x 1,6 m, no município de Campo Belo do Sul, SC ( $28^{\circ} 01^{\prime} \mathrm{S}, 50^{\circ} 52^{\prime} \mathrm{O}, 920 \mathrm{~m}$ de altitude, Figura 1), dentro da região bioclimática 1 do estado de Santa Catarina (Empresa Brasileira de Pesquisa Agropecuária, 1988). A área experimental recebeu roçadas anuais até pleno estabelecimento das plantas, o que aconteceu entre o $3-4^{\circ}$ ano. As árvores foram podadas até $3 \mathrm{~m}$ de altura e nenhum desbaste havia sido realizado até o momento da presente análise.

Aos 21 anos de idade do povoamento, 28 árvores foram derrubadas, sendo selecionados dois indivíduos por classe diamétrica (amplitude de $2 \mathrm{~cm}$ ) considerando toda a variação diamétrica existente. De cada indivíduo derrubado, foram coletados discos transversais a 0,2 e 3,2 m acima do nível do solo. Os discos foram secos em estufa e submetidos à sequência de lixamento, com o objetivo de possibilitar o estudo dos anéis de crescimento. Em cada disco foram traçados quatro raios, conectando a medula à casca, marcados com um ângulo de $90^{\circ}$ entre si, sendo o primeiro raio $45^{\circ}$ deslocado do maior raio, não medido (Tomazello Filho et al., 2001). Após a marcação dos raios e dos anéis anuais de crescimento verdadeiros, os discos foram digitalizados e a largura dos anéis medida em meio digital (Image Pro Plus, versão 4.5) com uma acurácia de 0,1 $\mathrm{mm}$. 
(a)

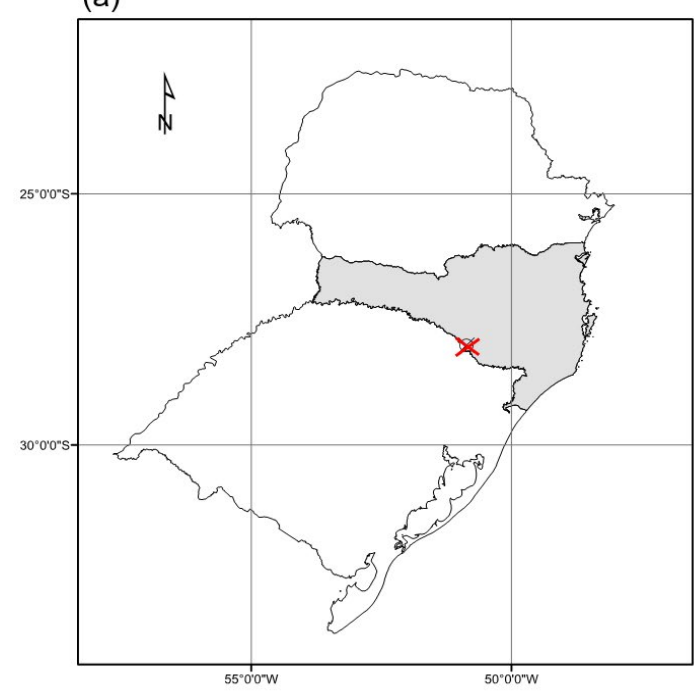

(b)

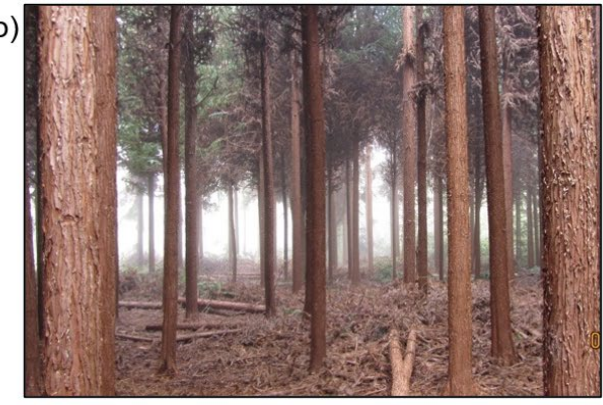

(c)

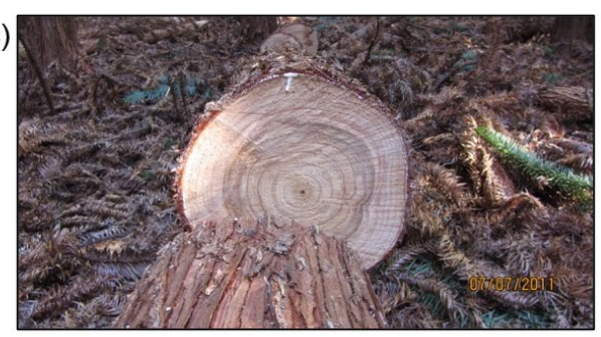

Figura 1. (a) Localização do povoamento de C. lanceolata objeto de estudo no planalto sul de Santa Catarina, (b) povoamento logo após o corte de alguns indivíduos para a coleta de seções transversais do fuste e (c) um corte transversal do fuste.

No momento da coleta dos discos, o povoamento apresentava densidade de 1.278 árvores ha-1 ${ }^{-1}$ diâmetro à altura do peito (dap) médio de $24,8 \mathrm{~cm}$ e área basal de $65,3 \mathrm{~m}^{2} \mathrm{ha}^{-1}$. O estoque volumétrico totalizava $590 \mathrm{~m}^{3}$ ha-1 (Dobner Júnior et al., 2017).

\subsection{Microdensitometria de raios-X}

Dentre as 28 árvores amostradas, oito indivíduos foram selecionados para os estudos microdensitométricos, de forma a representar toda a amplitude diamétrica existente. Destes, utilizou-se o disco transversal coletado a 3,2 m acima do nível do solo para os estudos de microdensitometria por raios X. O melhor segmento 'casca-medula-casca', formado pela combinação de dois raios dentre os quatro medidos, livre de imperfeições ou defeitos, foi utilizado para a análise do crescimento.

A partir da faixa de madeira 'casca-medula-casca', amostras do lenho com $2 \mathrm{~mm} \times 10 \mathrm{~mm}$ (espessura $\mathrm{x}$ largura), no sentido transversal, foram obtidas em equipamento de dupla serra. As amostras foram então acondicionadas em câmara climática $\left(24 \mathrm{~h}, 20^{\circ} \mathrm{C}, 60 \%\right.$ umidade relativa do ar) para estabilização da umidade da madeira a 12\%, conforme recomenda Amaral \& Tomazello Filho (1998).

As amostras do lenho foram escaneadas por varredura radial contínua com o equipamento QTRS-01X da Quintek Measurement System, tendo como resultado a leitura da densidade aparente a cada 0,008 mm, totalizando 19.294 leituras.

\subsection{Dendrocronologia}

Para o estudo das correlações entre as variáveis meteorológicas e o crescimento das árvores, foram utilizados dados da estação meteorológica pertencente à EPAGRI/CIRAM do município de Lages, SC, distante $60 \mathrm{~km}$ em linha reta do povoamento estudado. De acordo com a classificação de Köppen, na área de estudo predomina o clima do tipo $\mathrm{Cfb}$, mesotérmico, subtropical úmido, com verões frescos, sem estações secas definidas, com a ocorrência de geadas severas (Alvares et al., 2013). A precipitação oscilou entre 100-200 $\mathrm{mm} \mathrm{mês}^{-1}$, de acordo com os valores médios mensais durante o período estudado (1990-2011) (Figura 2). A temperatura média oscilou entre $11-21^{\circ} \mathrm{C}$, a máxima entre $24-32^{\circ} \mathrm{C}$ e a mínima entre -2 e $-11^{\circ} \mathrm{C}$. Além destas variáveis meteorológicas, foram avaliadas a umidade relativa do ar, o número de dias de chuva por ano e o número de dias com geada por ano. 


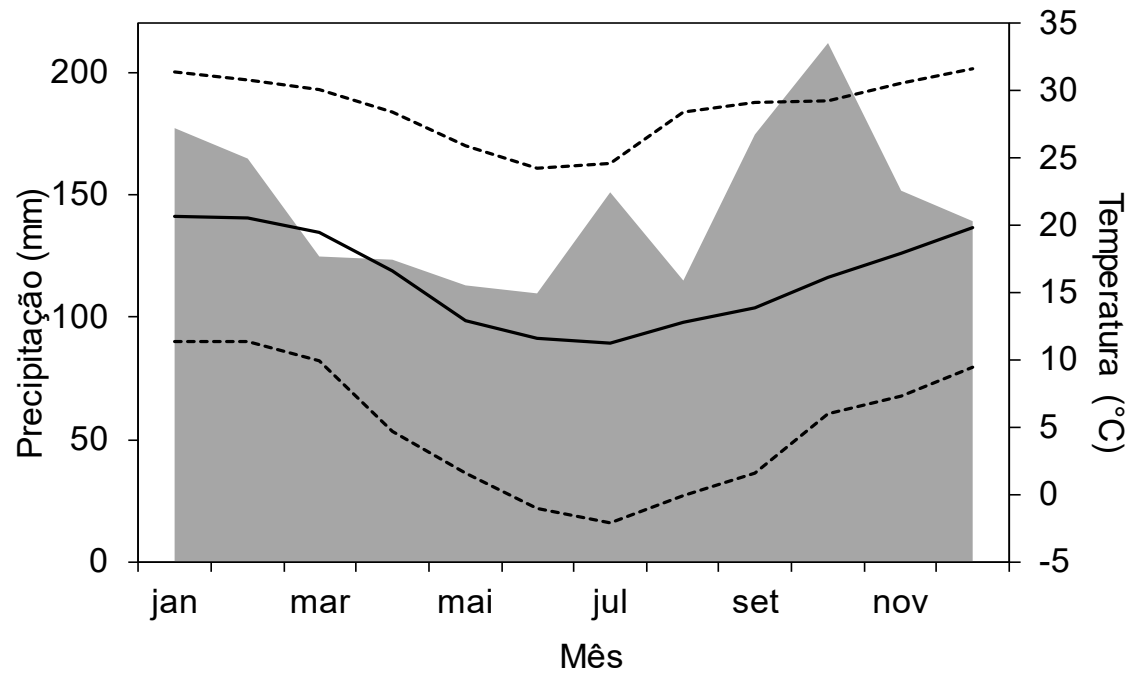

Figura 2. Valores médios mensais de precipitação (área em cinza), temperatura média (linha cheia), temperaturas máxima e mínima (linhas tracejadas) durante o período estudado (1990-2011).

A codatação dos anéis de crescimento das 28 árvores foi verificada com o auxílio do software COFECHA (Holmes et al., 1986; Grissino-Mayer, 1997), analisando períodos de $20 \mathrm{em}$ 20 anos com defasagem de 10 anos dentro de cada um destes. Tal amplitude de análise possui correlação crítica de $0,516(p<0,01)$ para a existência de similaridade entre os padrões de crescimento dos diferentes indivíduos.

Amostras com baixa correlação foram removidas de maneira a maximizar o sinal das séries utilizadas para construção da cronologia mestre. As séries de crescimento foram padronizadas com o auxílio do software 'ARSTAN' (Cook, 1985), com abordagem idêntica à aplicada por Mundo et al. (2012). A cronologia mestre gerada, ou índice de crescimento, possui valores que oscilam abaixo ou acima de ' 1 ', significando períodos de crescimento abaixo ou acima da taxa de crescimento médio para as árvores estudadas.

Em função da sobreposição do ano calendário com o período de crescimento vegetativo no hemisfério sul, o anel ' $n$ ', cuja formação do anel de crescimento foi concluída no outono/inverno do ano ' $n$ ', foi iniciado na primavera do ano ' $n-1$ '. Por este motivo, a comparação com dados meteorológicos incluiu os meses do ano calendário prévio ('p') e os do ano calendário corrente.

A cronologia dos anéis de crescimento foi correlacionada (correlação de Pearson) com dados meteorológicos mensais: precipitação acumulada, número de dias com chuva, temperatura (média, mínima e máxima) e umidade relativa do ar.

A padronização das séries de crescimento e a correlação com variáveis meteorológicas foram repetidas agrupando-se as árvores de acordo com as classes diamétricas: dominantes $(31-40 \mathrm{~cm})$, intermediárias $(21-30 \mathrm{~cm})$, e suprimidas $(12-20 \mathrm{~cm})$. Representando, desta forma, as taxas de crescimento nas diferentes classes sociológicas.

\section{RESULTADOS E DISCUSSÃO}

\subsection{Caracterização do lenho}

Os anéis de crescimento formados nas árvores de C. lanceolata (Figura 3) são caracterizados por uma diminuição da coloração conforme ocorre a transição do lenho inicial para o lenho tardio na imagem de raios $X$, sendo a maior densidade indicada pela coloração mais clara. O inverso é observado na imagem simples de uma seção transversal, com destaque para os anéis falsos, visível em ambas as imagens, e já relatado para a espécie por Tang et al. (2016). 
As leituras da densidade aparente e respectiva posição radial foram utilizadas para a construção de perfis radiais da densidade do lenho, conforme apresentado na Figura 4.
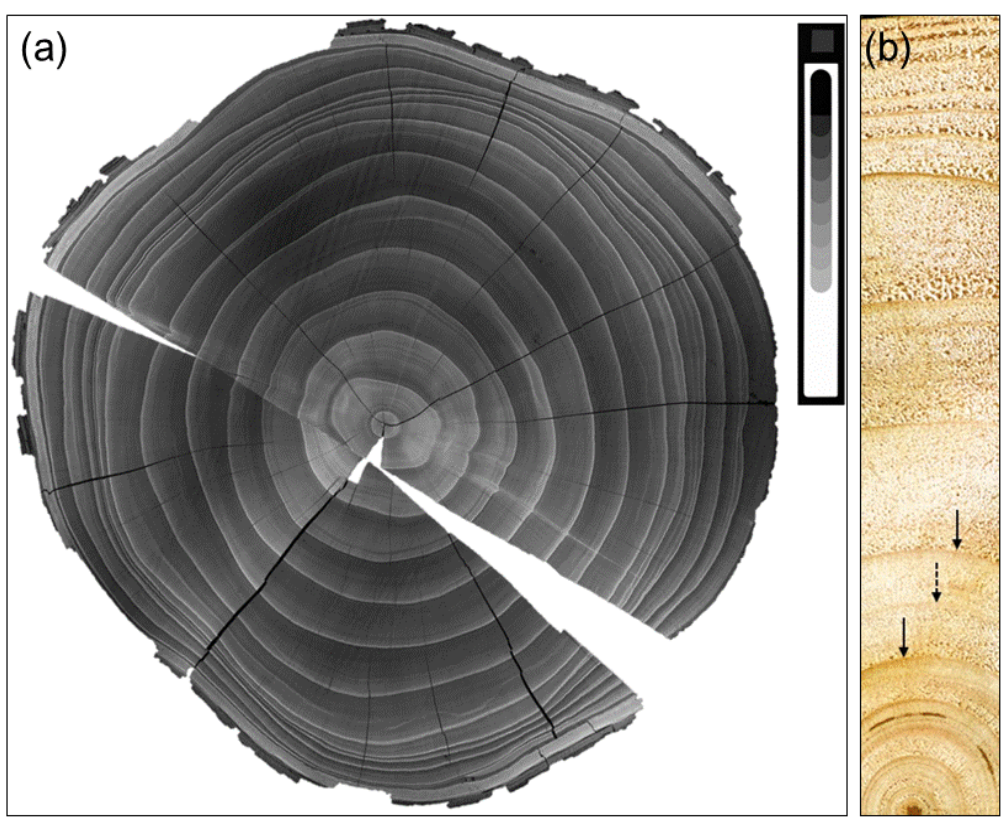

Figura 3. (a) Imagem de raios X e (b) caracterização macroscópica dos anéis de crescimento de Cunninghamia lanceolata. Setas contínuas indicam a delimitação dos anéis de crescimento; a seta pontilhada indica anel de crescimento falso.

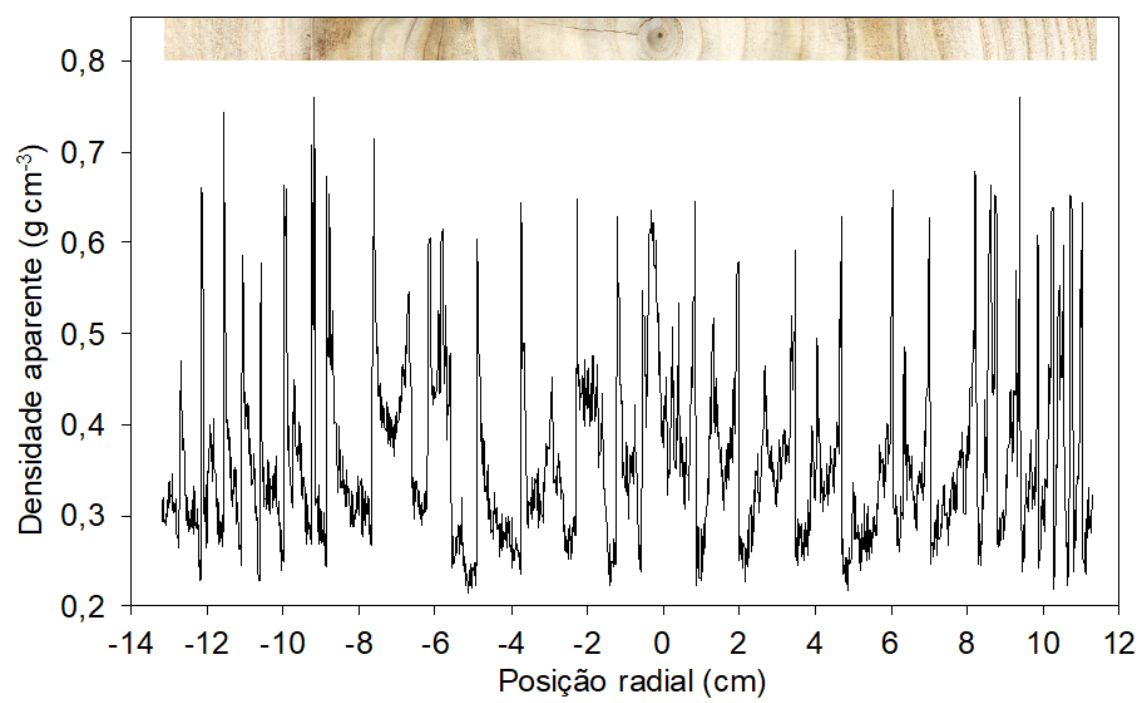

Figura 4. Perfil radial (casca-medula-casca) da densidade aparente (12\%) de uma das árvores de C. lanceolata analisadas, com $23,6 \mathrm{~cm}$ de diâmetro à altura do peito. $O$ 'zero' do eixo ' $x$ ' foi posicionado exatamente na medula.

Constatou-se que há variação da densidade aparente ao longo da posição radial, delimitando os anéis anuais de crescimento, bem como os lenhos iniciais e tardios, padrão este esperado para coníferas. As densidades aparentes média, mínima e máxima de todo o perfil radial (casca-medula) para as árvores avaliadas é apresentado na Tab. 1. 
Tabela 1. Densidade aparente média, mínima e máxima por árvore, ordenadas do menor para o maior diâmetro à altura do peito. A média geral e coeficiente de variação (CV) por variável analisada são também apresentadas.

\begin{tabular}{ccccc}
\hline \multirow{2}{*}{ Árvore } & \multirow{2}{*}{ dap $(\mathbf{c m})$} & \multicolumn{3}{c}{ Densidade aparente $\left(\mathbf{g ~ c m}^{-\mathbf{3}}\right)$} \\
\cline { 3 - 5 } & & média & mínima & máxima \\
\hline 1 & 11,2 & 0,377 & 0,166 & 0,748 \\
2 & 12,5 & 0,364 & 0,177 & 0,720 \\
3 & 14,8 & 0,344 & 0,166 & 0,658 \\
4 & 21,0 & 0,383 & 0,230 & 0,825 \\
5 & 23,6 & 0,358 & 0,215 & 0,761 \\
6 & 27,0 & 0,355 & 0,122 & 0,887 \\
7 & 32,7 & 0,364 & 0,200 & 0,789 \\
8 & 37,0 & 0,366 & 0,191 & 0,833 \\
media & 22,5 & 0,364 & 0,183 & 0,778 \\
CV(\%) & 42 & 3 & 18 & 9 \\
\hline
\end{tabular}

Observa-se na Tabela 1 que a densidade aparente média para todos os perfis radiais analisados foi de $0,364 \mathrm{~g} \mathrm{~cm}^{-3}$, podendo ser considerada uma madeira leve (Durlo, 1991), semelhante ao relatado por Lelles et al. (1978), 0,329 $\mathrm{g} \mathrm{cm}^{-3}$; e superior ao relatado por Marchiori (2005), 0,280 $\mathrm{g} \mathrm{cm}^{-3}$. Contatou-se uma baixa variação de densidade média entre os indivíduos, de 3\%, apesar destes diferirem substancialmente em termos de dap (42\%). Este resultado sugere não haver relação entre o ritmo de crescimento das árvores com a densidade média do lenho produzido. Ressalta-se que a baixa variação de densidade - ou homogeneidade de valores médios - é positiva para usos visando produtos de maior valor agregado (PMVA), mesmo em plantio com grandes variações de dap.

Na Figura 5 apresenta-se a densidade aparente média de acordo com a idade da formação do lenho para todos os indivíduos analisados. Constatou-se que a densidade média da madeira produzida ao longo do tempo (8-21 anos), a 3,2 m acima do nível do solo, foi relativamente constante (coeficiente de variação $=6 \%$ ) em torno dos valores médios, e permanecendo num patamar entre $0,350-0,400 \mathrm{~g} \mathrm{~cm}^{-3}$.

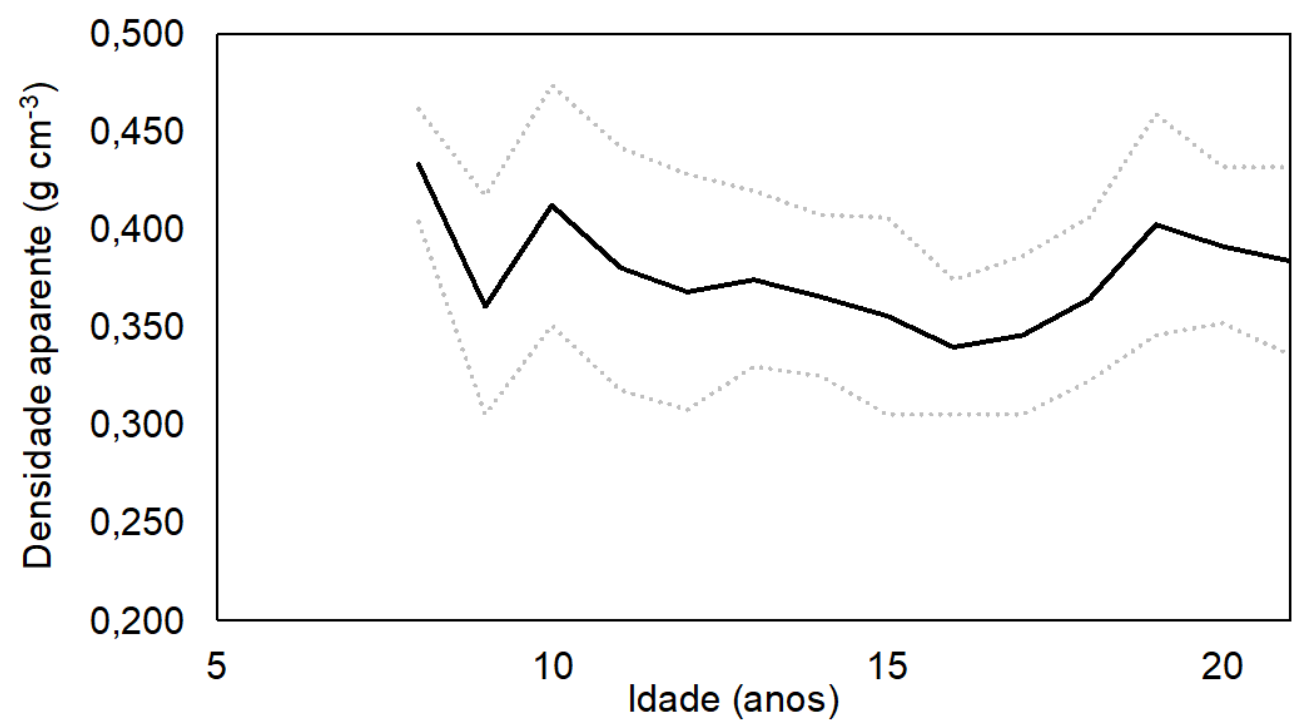

Figura 5. Densidade aparente média em função do ano de formação do lenho. Linhas pontilhadas indicam o desvio padrão da densidade no respectivo ano. 
Apesar de não terem sido encontrados trabalhos anteriores com C. lanceolata sobre este aspecto, esperava-se encontrar um padrão semelhante a Pinus $s p$. e outras coníferas, cuja densidade do lenho formado próximo a medula é inferior àquela formada a partir do $10-15^{\circ}$ ano de idade, caracterizando a transição entre os lenhos juvenil e adulto (Hennessey et al., 2004; Dobner Júnior et al., 2018).

Constatou-se, portanto, que a formação dos anéis anuais de crescimento em C. lanceolata ao longo dos anos foi relativamente constante em termos de densidade do lenho, o que é uma característica interessante para usos sólidos da madeira e corrobora com dados da Tab. 1. Desta forma, não foi possível distinguir lenho juvenil de adulto.

\subsection{Dendrocronologia}

Os primeiros anéis anuais de crescimento a 0,2 $\mathrm{m}$ acima do nível do solo foram detectados a partir do ano de 1994, 4-7 anos após o estabelecimento do povoamento. As árvores foram cortadas em julho de 2011, o último anel de crescimento analisado foi, portanto, aquele formado entre a primavera de 2010 e o outono de 2011. Desta forma, o período no qual foram analisadas correlações entre as séries de crescimento e as variáveis meteorológicas foi de 1994 a 2010, por ser o período comum entre os indivíduos. O número de anéis anuais de crescimento por indivíduo variou de 14 a 17, apesar de todas as árvores possuírem 21 anos de idade. $O$ trabalho criterioso de demarcação dos anéis de crescimento, com auxílio das análises microdensitométricas, permite afirmar que não houve falhas nesta importante etapa do trabalho, tanto em relação à correta delimitação de anéis verdadeiros como na não demarcação de falsos anéis. A falta de anéis é discutida em maior profundidade mais adiante, juntamente com a análise das variáveis meteorológicas.

Das 28 árvores amostradas, 24 foram utilizadas nas análises dendrocronológicas em função da baixa correlação das séries de crescimento de alguns indivíduos. As 24 séries de crescimento analisadas apresentaram uma intercorrelação de 0,543 , superior ao valor crítico de $0,515(p<0,01)$, indicando existir correlação positiva e significativa entre as séries e, permitindo, assim, a construção de uma série indexada de crescimento (Figura 6).

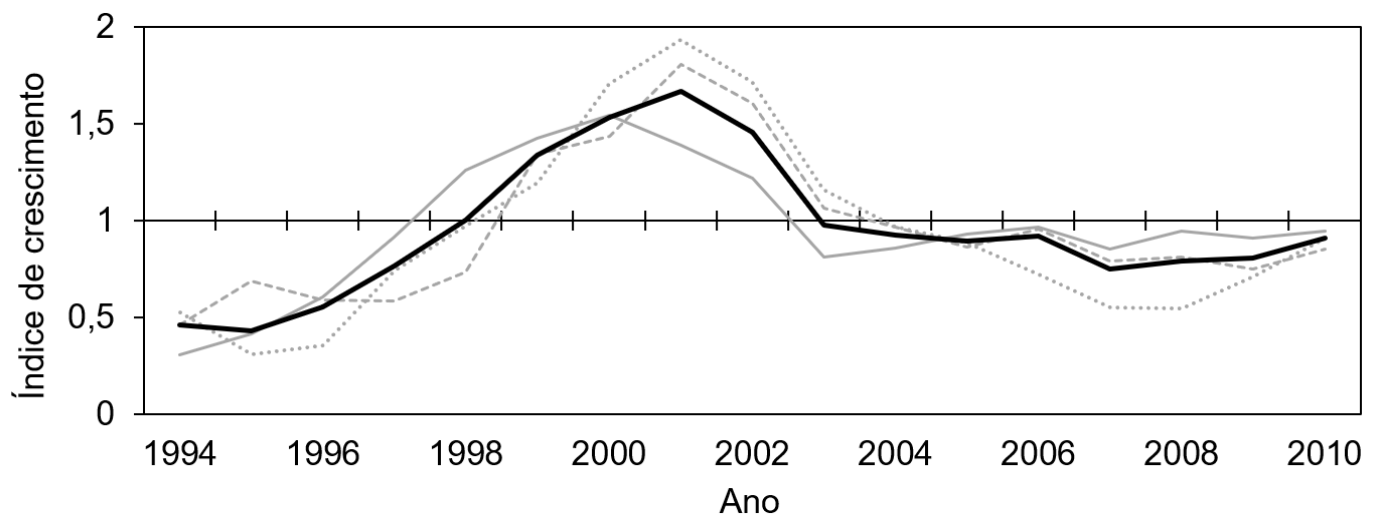

Figura 6. Cronologia indexada de Cunninghamia lanceolata durante o período de 1994 a 2010: todas as árvores (linha preta); árvores dominantes (linha cinza); árvores intermediárias (linha tracejada); árvores suprimidas (linha pontilhada).

A cronologia dos anéis de crescimento representa a curva padronizada do crescimento. Observa-se na Figura 6 que o período entre os anos de 1996 e 2001 (5-11 anos de idade) foi caracterizado por um ritmo de crescimento ascendente, decrescendo na sequência e estabilizando após 2004, aos 14 anos de idade. As correlações entre a cronologia dos anéis de crescimento e as variáveis meteorológicas são apresentadas na Figura 7. 

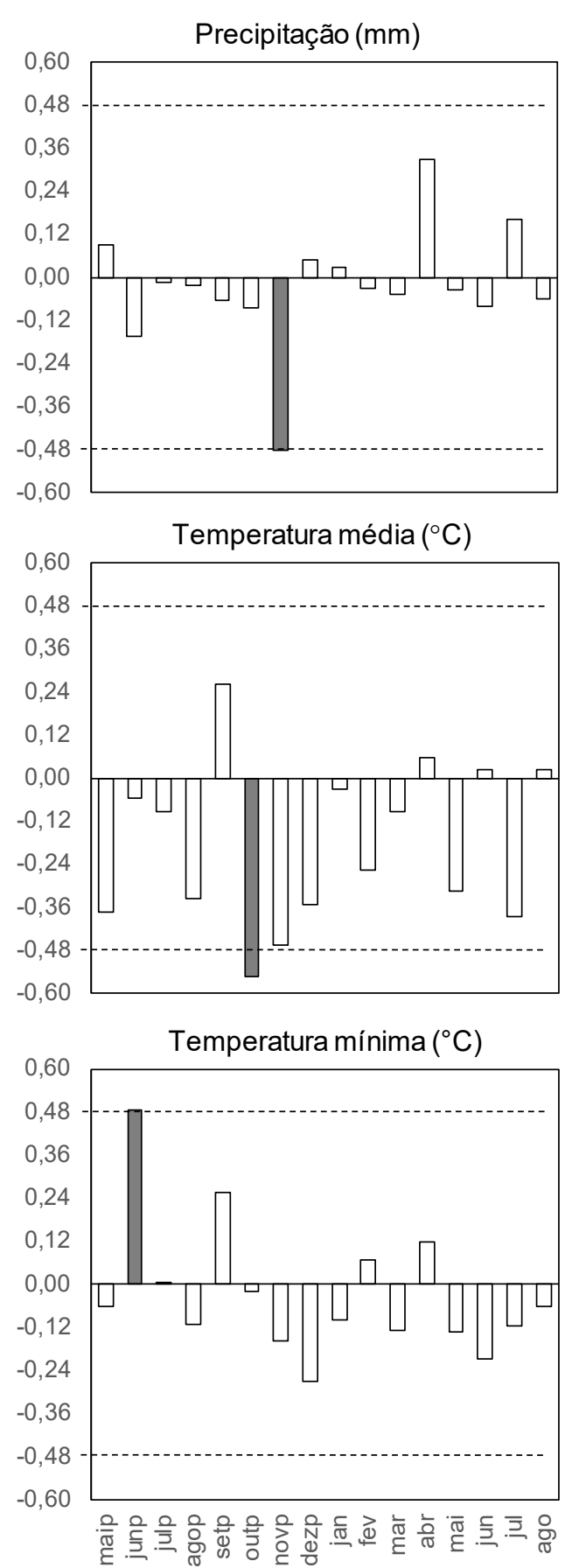

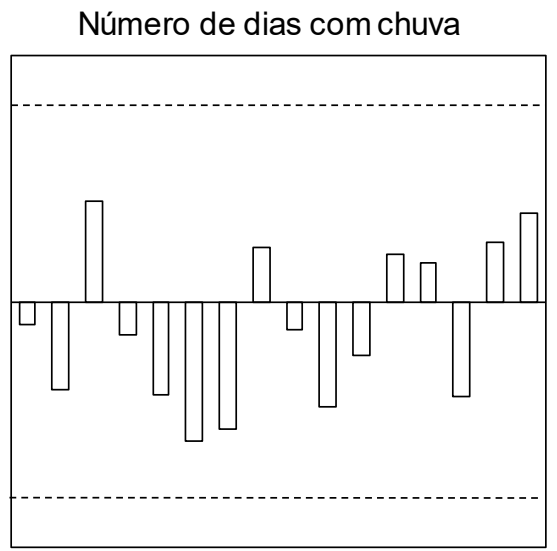

Temperatura máxima $\left({ }^{\circ} \mathrm{C}\right)$
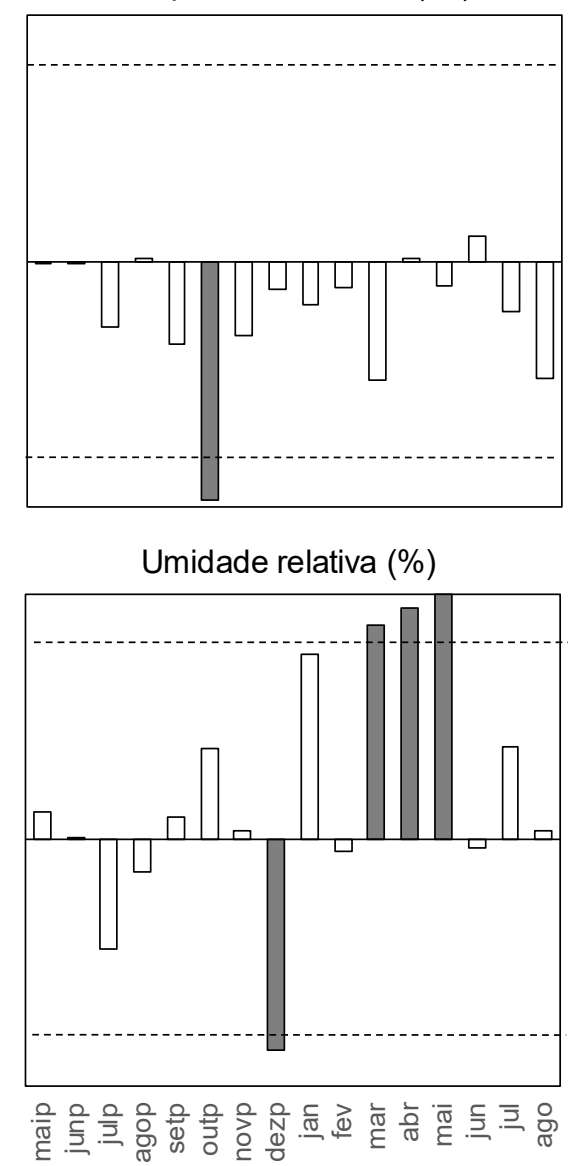

Figura 7. Coeficiente de correlação entre o crescimento indexado de $C$. lanceolata e as respectivas variáveis meteorológicas mensais do ano prévio ( $p$ ) e corrente da formação do anel, no período de 1994 a 2010. Linhas pontilhadas indicam o limite de significância $( \pm 0,48 ; p<0,05)$. Meses com correlação significativa estão destacados em cinza.

Constatou-se que a precipitação do mês de novembro prévio apresentou correlação significativa e negativa. A pouca influência da disponibilidade de água no solo já era esperada, considerando que o local de estudo possui chuvas bem distribuídas durante todo o ano, possuindo raros períodos de déficit hídrico (Ullmann, 1985; Soccol et al., 2005) e estes, provavelmente, imperceptíveis para árvores plenamente estabelecidas. A correlação negativa com a precipitação de novembro indica que a quantidade de água no solo atingiu níveis prejudiciais ao crescimento de $C$. lanceolata. Constatou-se que outubro foi o mês de maior precipitação média durante o período estudado, possivelmente com implicações no crescimento do mês seguinte e explicando a significância estatística detectada. Este resultado 
reforça o relatado por Instituto de Pesquisas e Estudos Florestais (1976), que C. lanceolata é uma espécie exigente quanto à capacidade de drenagem do solo.

Não foi detectada correlação significativa entre o crescimento de $C$. lanceolata e o número de dias com chuva no mês. Esta constatação tem relação com o já discutido para a precipitação. A região onde o estudo foi conduzido possui precipitação bem distribuída ao longo do ano de forma que a disponibilidade hídrica não é limitante ao crescimento. Fato este reforçado pela ausência de correlação com o número de dias com chuva no mês.

Constatou-se correlação negativa significativa da temperatura média e máxima do mês de outubro, início da formação do anel anual, indicando que primaveras quentes podem ter sido prejudiciais ao crescimento de $C$. lanceolata.

Adicionalmente, constatou-se que o crescimento de $C$. lancelolata no período estudado foi significativamente e positivamente correlacionado com a temperatura mínima do mês de junho prévio ao início da formação do anel, indicando que a severidade do inverno anterior ao início do crescimento é um fator limitante.

O fato de os primeiros anéis anuais de crescimento terem sido detectados 4-7 anos após o plantio das árvores, mesmo tendo sido analisados a 0,2 $\mathrm{m}$ acima do nível do solo, indica que o crescimento inicial de $C$. lanceloata foi negativamente influenciado, provavelmente pelo frio. Pode-se inferir, portanto, que o crescimento da espécie respondeu positivamente a invernos de menor intensidade, reforçando a baixa tolerância às geadas de $C$. lanceolata relatadas por Instituto de Pesquisas e Estudos Florestais (1976) e Dobner Júnior et al. (2017).

Analisando em maior detalhe os dados meteorológicos da estação de Lages, SC, constatou-se que os meses de maio $\left(7,9^{\circ} \mathrm{C}\right)$ e agosto $\left(0,7^{\circ} \mathrm{C}\right)$ do ano de 1994 foram os que apresentaram temperaturas mais amenas durante os anos estudados, nos quais foram constatadas temperaturas de até $-4,8^{\circ} \mathrm{C}$ em agosto no de 1991 e $-2,1^{\circ} \mathrm{C}$ em maio de 1993. Além disso, segundo a mesma fonte, foram registradas quatro geadas fortes nos anos de 1992 e 1993, enquanto em 1994 houve apenas uma ocorrência. A hipótese dos autores para justificar a ausência de quatro anéis anuais de crescimento à $0,2 \mathrm{~m}$ de altura é que os indivíduos tiveram a parte aérea totalmente danificada por geadas nos primeiros anos logo após o estabelecimento, rebrotando logo em seguida

Shengtao et al. (2019) estudaram o efeito de variáveis meteorológicas no crescimento de C. lancelolata em florestas secundárias nativas no sudeste da China. Os autores concluíram ser possível extrair boas cronologias e informações climáticas de indivíduos crescendo em ambiente subtropical. De forma semelhante ao verificado no presente estudo, detectaram correlação negativa do crescimento com a precipitação em meses nos quais esta variável apresentava valores altos e, consequentemente, saturação do solo. Conforme já mencionado, resultado da exigência de solos bem drenados da espécie. Diferente do observado no presente estudo, detectaram correlação positiva do crescimento com a temperatura média mensal dos meses da primavera. Este não é um resultado necessariamente contraditório, visto que os locais de estudo são substancialmente distintos em termos meteorológicos.

Estudos para outras espécies indicam que além da temperatura baixa durante o inverno, outro fator limitante ao crescimento de espécies pouco tolerantes às geadas no planalto sul do Brasil é a oscilação térmica (Dobner Júnior et al., 2009). Entretanto, não foi detectada correlação significativa da oscilação térmica mensal $\left(T_{\operatorname{máx}}-T_{\min }\right)$ com o crescimento das árvores estudadas, motivo pelo qual esta análise não é apresentada na Figura 5.

A umidade relativa dos meses de março, abril e maio foi positiva e significativamente correlacionada com o crescimento das árvores. A consistência destes resultados, detectado para três meses consecutivos, indica forte dependência deste fator no crescimento das árvores. Uma hipótese seria o fato dos meses de março, abril e maio possuírem, em termos médios, precipitações baixas em comparação com o restante do ano. Nos anos em que a umidade relativa do ar foi maior neste período, os processos fisiológicos relacionados ao crescimento podem ter sido beneficiados. O fato da umidade relativa de dezembro ter sido significativamente e negativamente correlacionada com o crescimento das árvores pode estar relacionado com a correlação negativa observada para a precipitação do mês de novembro prévio, conforme já relatado. 
A correlação do padrão de crescimento das árvores separadas por classe sociológica foi semelhante à observada para as árvores analisadas em conjunto, indicando que as variáveis meteorológicas possuem efeito semelhante, independentemente da posição sociológica dos indivíduos, possivelmente por se tratar de um plantio equiâneo e monoespecífico.

\section{CONCLUSÕES}

A caracterização do lenho de Cunninghamia lanceolata por meio de microdensitometria de raios $\mathrm{X}$ indicou que a densidade aparente média do lenho de indivíduos cultivados no sul do Brasil é de $0,364 \mathrm{~g} \mathrm{~cm}^{-3}$, semelhante em árvores de menor ou maior crescimento em diâmetro aos 21 anos de idade. Não há diferenças significativas entre a densidade aparente do lenho formado próximo à medula (juvenil) e o lenho próximo à casca (adulto), o que é positivo para a fabricação de produtos com madeira sólida.

$\mathrm{O}$ crescimento em diâmetro de indivíduos de $C$. lanceolata cultivados no planalto sul do Brasil é significativamente e positivamente afetado pela temperatura mínima do mês de junho prévio ao início do período vegetativo, e pela umidade relativa do ar dos meses de março, abril e maio, término do período vegetativo. Além do efeito negativo de geadas no crescimento durante todo o período estudado, a ausência de 4-7 anéis de crescimento na base da árvore indica que geadas são, possivelmente, o maior fator limitante para o estabelecimento de plantios da espécie na região estudada.

\section{AGRADECIMENTOS}

Os autores são gratos à Florestal Gateados pelo suporte e ao Laboratório de Anatomia, Identificação e Densitometria de Raios X em Madeira do LCF/ESALQ/USP pelas análises.

\section{REFERÊNCIAS BIBLIOGRÁFICAS}

Alvares, C. A., Stape, J. L., Sentelhas, P. C., Moraes Gonçalves, J. L., \& Sparovek, G. (2013). Köppen's climate classification map for Brazil. Meteorologische Zeitschrift (Berlin), 22(6), 711-728. http://dx.doi.org/10.1127/0941-2948/2013/0507.

Amaral, A. C. B., \& Tomazello Filho, M. (1998). M. Avaliação das características dos anéis de crescimento de Pinus sp. através da densitometria de raios X. Ciência e Tecnologia, 11/12(6), 17-23.

Cook, E. R. (1985). A time series analysis approach to tree ring standardization (Tese de doutorado). University of Arizona, Arizona.

Dobner Júnior, M., Higa, A. R., \& Seitz, R. A. (2009). Efeito da cobertura de Pinus taeda L. na proteção contra geadas e no crescimento de plantas jovens de Eucalyptus dunnii Maiden. Floresta, 39(4), 807823. http://dx.doi.org/10.5380/rf.v39i4.16315.

Dobner Júnior, M., Huss, J., \& Tomazello Filho, M. (2018). Wood density of loblolly pine trees as affected by crown thinnings and harvest age in southern Brazil. Wood Science and Technology, 52(2), 465-485. http://dx.doi.org/10.1007/s00226-017-0983-9.

Dobner Júnior, M.,Trazzi, P. A., Machado, S. D. A., \& Higa, A. R. (2017). Aspectos dendrométricos e silviculturais de um povoamento de Cunninghamia lanceolata no sul do Brasil. Floresta, 47(1), 1-9. http://dx.doi.org/10.5380/rf.v47i1.43562.

Durlo, M. A. (1991). Tecnologia da madeira: peso específico (29 p.). Santa Maria: Universidade Federal de Santa Maria.

Empresa Brasileira de Pesquisa Agropecuária - EMBRAPA. (1988). Zoneamento ecológico para plantios florestais no estado de Santa Catarina. Curitiba: Centro Nacional de Pesquisas Florestais.

Grissino-Mayer, H. D. (1997). Computer assisted, independent observer, verication of tree-ring measurements. Tree-Ring Bulletin, 54, 29-41.

Hennessey, T. C., Dougherty, P. M., Lynch, T. B., Wittwer, R. F., \& Lorenzi, E. M. (2004). Long-term growth and ecophysiological responses of a southeastern Oklahoma loblolly pine plantation to early rotation thinning. Forest Ecology and Management, 192(1), 97-116. http://dx.doi.org/10.1016/j.foreco.2004.01.008.

Holmes, R. L., Adams, R. K., \& Fritts, H. C. (1986). Quality control of crossdating and measuring: a user manual for program COFECHA. In R. L. Holmes, R. K. Adams \& H. C. Fritts (Eds), Tree rings 
chronologies of Western North America: California, eastern Oregon and northern Great Basin. Tucson: Arizona University.

Instituto de Pesquisas e Estudos Florestais - IPEF. (1976). Zoneamento ecológico para o reflorestamento de regiões tropicais e subtropicais. Boletim Informativo, 4(13), 11-17.

Lei, J. F. (2005). Forest resource in China (em chinês). Beijing: China Forestry Publishing House.

Lelles, J. G., Souza, A. P., Clemente, V. M., \& Valente, O. F. (1978). Estudo das características da celulose Kraft de Cunninghamia lanceolata Lamb. Revista Árvore, 2(1), 34-40.

Marchiori, J. N. C. (2005). Dendrocronologia das gimnospermas (2. ed.). Santa Maria: UFSM.

Minghe, L., \& Ritchie, G. A. (1999). Eight hundred years of clonal forestry in China: I. traditional afforestation with Chinese fir (Cunninghamia lanceolata (Lamb.) Hook.). New Forests, 18(2), 131-142. http://dx.doi.org/10.1023/A:1006558900234.

Mundo, I. A., Roig Junent, F. A., Villalba, R., Kitzberger, T., \& Barrera, M. D. (2012). Araucaria araucana tree-ring chronologies in Argentina: spatial growth variations and climate influences. Trees (Berlin), 26(2), 443-458. http://dx.doi.org/10.1007/s00468-011-0605-3.

Shengtao, L., Peng, G., Panwei, L., Xiang, N., \& Bing, W. (2019). The response of Chinese fir forest tree ring growth to climate change in China's Dagangshan Region. Polish Journal of Environmental Studies, 28(4), 2371-2379. http://dx.doi.org/10.15244/pjoes/91788.

Soccol, O. J., Ullmann, M. N., Prado, G., \& Cunha, D. L. (2005). Balanço hídrico para o município de LagesSC. In Congresso Nacional de Irrigação e Drenagem (pp. 1-6). Brasília: Associação Brasileira de Irrigação e Drenagem.

Tang, X., Lu, Y., Fehrmann, L., Forrester, D. I., Guisasola-Rodríguez, R., Pérez-Cruzado, C., \& Kleinn, C. (2016). Estimation of stand-level aboveground biomass dynamics using tree ring analysis in a Chinese fir plantation in Shitai County, Anhui Province, China. New Forests, 47(2), 319-332. http://dx.doi.org/10.1007/s11056-015-9518-0.

Tomazello Filho, M., Botosso, P. C., \& Lisi, C. S. (2001). Análise e aplicações dos anéis de crescimento das árvores como indicadores ambientais: dendrocronologia e dendroclimatologia. In N. B. Maia, H. L. Martos \& W. Barella (Eds.), Indicadores ambientais: conceitos e aplicações. São Paulo: Educ.

Ullmann, M. N. (1985). Balanço hídrico para Lages - SC para culturas de raízes superficiais e moderada profundidade (20 p.). Lages: [s.n.].

Xiang, W., Chai, H. X., Tian, D. L., \& Peng, C. H. (2009). Marginal effects of silvicultural treatments on soil nutrients following harvest in a Chinese fir plantation. Soil Science and Plant Nutrition, 55(4), 523-531. http://dx.doi.org/10.1111/j.1747-0765.2009.00384.x.

Contribuição dos Autores: MDJ: conceituação, curadoria dos dados, análise formal, investigação, metodologia, validação, escrita - primeira redação, escrita - revisão e edição; PAT: análise formal, investigação, metodologia, escrita - revisão e edição; ULB: análise formal, metodologia, escrita - revisão e edição; IRO: análise formal, metodologia, escrita - revisão e edição; MTF: análise formal, metodologia, escrita - revisão e edição. 